\title{
Traducción y edición de textos antiguos portugueses en la era de la hipertextualidad: una experiencia desde México
}

Translation and edition of old Portuguese texts in the era of hypertextuality: an experience from Mexico

\author{
Alma Delia Miranda ${ }^{1}$
}

Resumen: El artículo muestra la necesidad de ediciones y traducciones hipertextuales, útiles sobre todo para el estudio de textos anteriores al siglo XVIII, pero también de obras modernas que se podrán beneficiar de los avances de la tecnología, porque estas herramientas implican una mayor y más profunda internacionalización de la literatura portuguesa, como se puede constatar mediante una experiencia desde México.

Palabras Claves: Edición; traducción; hipertextualidad; literatura anterior al siglo XVIII.

\begin{abstract}
The article shows the necessity of hypertext editions and translations, mainly useful for the study of literature written before the Age of Enlightenment, but also for more modern literature that could benefit from technological advances, because these tools imply a greater and deeper internationalization of Portuguese literature, as it is possible to verify through this experience from Mexico.
\end{abstract}

Keywords: Publishing; translation; hypertext; literature before the Age of Enlightenment.

\footnotetext{
${ }^{1}$ Colegio de Letras Modernas, Facultad de Filosofía y Letras, Universidad Nacional Autónoma de México (México).
} 
En el comienzo de «The translator's study. Picturing translation from Saint Jerome to Nurith Aviv», Sherry Simon (2019) reflexiona a partir de la transformación de las representaciones de San Jerónimo, quien pasa de asceta en el desierto a filólogo en un estudio equipado. El repaso de Simon, del San Jerónimo de Giovanni di Paolo, de Ghirlandaio o de Antonello Da Messina hasta llegar a los documentales de Nurith Aviv, puede ser el trampolín para dar el salto a la revisión de otras representaciones en la pintura del acto de escribir y constatar que en todos los ejemplos existe algo que nuestra época ha perdido: los personajes representados se disponen a escribir el texto definitivo porque en todas está presente la mano con la pluma a punto de posarse en una hoja, en un cuaderno o en un papel. Qué mundo lejano ése. $Y$ es que, por lo que parece, la pintura ha sido incapaz de acompañar el devenir del acto de escribir: aunque hoy en día trabajemos aún en un estudio, rodeándonos de libros impresos, el avance de la tecnología implica: a) que, durante el proceso, nuestro «original» sea un texto muy susceptible a la corrección y en constante transformación, lejos del carácter definitivo como el que representan los cuadros, porque se retrasa al límite la versión final, b) aproxima la biblioteca al propio dispositivo en el que también se trabaja,y c) es más frecuente nuestro contacto corporal con un teclado y una pantalla con numerosas ventanas. Quienes formamos parte de la cultura escrita profesional sabemos que, en el mundo de hoy, nuestro ejercicio, a pesar de no haber perdido el contacto con el papel y la pluma, significa estar en contacto de manera preponderante con los dispositivos tecnológicos y con el proceso hipertextual.

Es innegable el entusiasmo que ha despertado en las comunidades académicas la experiencia del aprovechamiento de las posibilidades que plantean los recursos hipertextuales en el ámbito educativo, sobre todo en el bienio 2020-2021, en que la mayor parte de la labor intelectual se ha llevado a cabo no en las bibliotecas universitarias y centros de investigación, sino en los hogares, sacando el máximo provecho de los recursos digitales: libros electrónicos, libros digitalizados, bibliotecas digitales, blogs, videoblogs, charlas grabadas, audiolibros, diccionarios en línea, podcasts, congresos y conferencias virtuales. Estos recursos se han convertido en herramientas preciosas que nos permiten superar barreras físicas y temporales porque, aparentemente, todo lo que se produce en el presente y lo que se ha producido en el pasado está ahí, al alcance de un clic. Sin embargo, el resultado de las búsquedas relacionadas con los textos antiguos, en este caso portugueses, nos regala un innegable campo de oportunidades al cotejar la desigual calidad de los materiales que son objeto de estudio, sea desde el ámbito de la traducción o la edición. La valoración de lo logrado, y lo que sería conveniente hacer para el futuro, será el objeto de mi trabajo, que se concretará en la propuesta de 
la conveniencia de ediciones hipertextuales de textos antiguos, basada en mi experiencia como profesora de literatura antigua portuguesa y traductora desde México, es decir, lejos de la mayoría de los recursos impresos que se producen en Portugal.

\section{Notas sobre la traducción} portugués-español antes

\section{de la era de la hipertextualidad}

El recorrido diacrónico por la historia de la traducción del portugués al español no debería de implicar únicamente la realizada desde España a partir de originales portugueses, sino que debería de incluir las realizadas en los países hispánicos a partir de originales en lengua portuguesa. Es evidente que, por cuestiones geográficas, las traducciones hechas en España se remontan a siglos atrás (Dasilva, 2017); pero, si pensamos en épocas más recientes, en algún momento debería realizarse por lo menos un estudio que dé cuenta del estado de la cuestión, tanto en España como en los países hispanoamericanos, con una industria editorial de peso considerable: Argentina, Chile, Colombia, Cuba y México, sobre todo. Por ahora se encuentran de manera dispersa aportaciones generales, pero ilustrativas, como la que realiza Alejandrina Falcón (2016) en un trabajo que aborda las representaciones de la traducción, los criterios de selección y las formas de traducir de la Argentina de finales de los años 60, en donde registra «reediciones de traducciones de literatura brasileña», pero nos quedamos con la duda que cuáles serán los títulos; en cambio, queda muy clara la hegemonía del inglés.

Además, esa historia de la traducción literaria del portugués al español no debería de abarcar únicamente nombres de autores o títulos traducidos en un determinado espacio geográfico, sino que también debería de tomar en cuenta las políticas culturales que propiciaron, o frenaron, la traducción de textos literarios originados en los diferentes países lusófonos. A lo anterior debería de añadirse otro elemento que resulta importante de historiar: el proceso de traducción realizado antes del desarrollo tecnológico, dado que éste tuvo lugar en una época en la que no abundaban los materiales o herramientas que hoy tenemos, lo cual pudo conllevar numerosos errores de traducción. Sin duda alguna, no se debe pasar por alto la historia del proceso de traducción ni la vinculación de éste con el proceso de aprendizaje del portugués en los países de habla española. Antes de la instauración de programas de sistemático intercambio académico entre los países lusófonos y los países hispanoamericanos, y antes del desarrollo de las herramientas tecnológicas, el conocimiento de la lengua portuguesa se limitaba a circunstancias muy acotadas, más ligadas a cuestiones biográficas que a proyectos académicos o culturales de considerable alcance 
cuantitativo y cualitativo. ${ }^{2}$ Por todo lo anterior, no sería raro toparse con traducciones que se ejecutaron sin que quienes las realizaron efectivamente hubieran estudiado la lengua, por ejemplo, sino que más bien lo llevaron a cabo impulsados por la creencia de que tenían alta capacidad lectora en portugués, sin que esto necesariamente implicara que pudieran traducir. Apoya lo anterior Elena Losada, al referirse a las traducciones de las obras de Eça de Queirós en España:

Hasta 1920 - y con pocas excepciones - se trata de una historia de traducciones mal pagadas, hechas a toda prisa, a veces cedidas a terceros que solían tener un conocimiento muy deficitario de la lengua de origen. En el caso de las traducciones del portugués la situación se veía agravada por la falsa familiaridad que un hablante de castellano o de catalán tiene ante la lengua escrita, error que se paga, todavía hoy, con grotescos contrasentidos. (Losada, 2001: 171)

Me gustaría enfatizar el todavía hoy de 2001, porque es el año que propongo como momento de corte entre un proceso de traducción netamente basado en fuentes impresas y el que está vigente, que es un proceso hipertextual. En síntesis: en el pasado, sin la posibilidad de viajar a los países lusófonos, con escasez de diccionarios y con un conocimiento precario de la lengua (provocado por un débil desarrollo de los materiales y escasez de input), el proceso de traducción del portugués al español implicaba un trabajo con desiguales resultados, porque ¿cómo traducir bien una lengua que se conoce mal? Es por esto que las traducciones bien realizadas antes de la explosión de Internet merecen un amplio reconocimiento.

\section{La traducción portugués-español en la era de la hipertextualidad}

Uno de los triunfos innegables de la masificación de la tecnología ha sido una mayor democratización del conocimiento, incluido el de las lenguas extranjeras, aunque evidente y lamentablemente quien está fuera del acceso a la tecnología no puede participar de lo que ésta ofrece. Mientras que antes sólo quien tuviera recursos económicos abundantes podía alcanzar el aprendizaje de una lengua extranjera y, por lo tanto, ejercer la enseñanza o traducción, hoy existen más posibilidades de aprender lenguas y surgen más herramientas que facilitan tanto la profundización en el conocimiento de los idiomas como los traslados de una lengua a otra: materiales virtuales,

\footnotetext{
${ }^{2}$ Complementa lo anterior la historia de los propios materiales de aprendizaje de la lengua portuguesa, investigación avanzada en lo que a España se refiere. Ponce de León Romeo (2009) ubica sólo en el último tercio del siglo XIX el inicio más sistemático de los manuales para aprender portugués, aunque en el año de publicación de su artículo los considera aún insuficientes. Pero añade también consideraciones importantes en el orden de los prejuicios lingüísticos, según los cuales habría existido una creencia arraigada de que el portugués era un dialecto del español, lo cual creó una idea falaz de superioridad lingüística de una lengua en relación con la otra.
} 
diccionarios en línea, foros de discusión de uso de palabras en contextos lingüísticos determinados, foros de consulta de dudas, tándems lingüísticos e, incluso, traductores automáticos que pueden resultar útiles para vocabulario o breves textos muy determinados que no impliquen ningún uso creativo de la lengua, por lo que no son muy útiles para la traducción literaria. El desarrollo tecnológico facilita el proceso de un ejercicio abundante de traducción, que va desde la acción «inocente» de poner en la lengua materna lo que dice una canción en otro idioma hasta la traducción profesional de literatura. $Y$ en este último ámbito, un espacio aparte merece el proceso de traducción de textos antiguos porque se ve altamente beneficiado por la existencia de herramientas impensables antes de 2001, año de aparición de Wikipedia, ese proyecto educativo colaborativo, en constante expansión y transformación, esa primera gran empresa de la hipertextualidad que lideró un movimiento masivo hacia lo que con el tiempo se ha convertido en un buen número de bibliotecas digitales.

Casi 40 años antes, en 1965, Ted Nelson introducía por primera vez el término hypertext para definir:

a body of written or pictorial material interconnected in such a complex way that it could not conveniently be presented or represented on paper. It may contain summaries, or maps of its contents and their interrelations; it may contain annotations, additions and footnotes from scholars who have examined it. Let me suggest that such an object and system, properly designed and administered, could have great potential for education, and his intellectual grasp. Such a system could grow indefinitely, gradually including more and more of the world's written knowledge. (Nelson, 1965: 96)

Buena parte de la descripción de Nelson encaja en lo que posteriormente serán recursos wiki, cuyo desarrollo va de la mano del abandono de las máquinas de escribir y la aparición de procesadores de textos y dispositivos de almacenamiento que nos transportaron a un mundo en el que podemos trabajar y reescribir en nuestro archivo al mismo tiempo que vamos dejando marcas que resaltan dudas o alternativas para resolver después, o que ofrece herramientas para rastrear una determinada palabra a lo largo de nuestro texto. En otras palabras, el proceso por el que hoy transitamos camino a nuestro texto definitivo, nuestra versión final, difiere de aquello representado en la pintura a través de los siglos, como muestran los cuadros sobre San Jerónimo a los que alude Sherry Simon. Por eso, un medio que incorpora el movimiento, como el video, es el soporte que mejor puede acompañar ese proceso, y no la pintura, que es estática y cuyo propio desarrollo ya no suele representar realistamente el mundo.

Deseo enfatizar que esta revolución en el proceso de escritura y en el de consulta de fuentes viene a facilitar el ejercicio de traducción de 
textos literarios anteriores al siglo XVIII, muy escasamente visitados incluso ahora, porque implica un trabajo semejante al de la edición crítica y anotada de las obras de periodos pasados. En ambos casos, la finalidad es proporcionar al lector un texto fiable y con un óptimo grado de legibilidad. Para lograrlo, tanto al editar como al traducir, se emprende un considerable trabajo de investigación en el que es esencial contar con la bibliografía adecuada para lograr los objetivos. En este sentido, la cabal comprensión del texto base, para poder ofrecer otro igualmente fiable en la lengua de llegada, implica no sólo saber las lenguas, sino también tener cercanía con los usos lingüísticos anteriores al siglo XVIII, además de realizar un trabajo arduo de investigación en fuentes de la época, o más cercanas en el tiempo a esos textos. La utilidad de obras tan fundamentales como el Vocabulário de Rafael Bluteau (1712-1728), en lo que respecta al sentido de las palabras, ilustra sobre el antes y después en el proceso de traducción. ¿Cuántas bibliotecas en el mundo, fuera de Portugal, podían haber tenido en su acervo esta fuente? Antes de que se pudiera consultar en línea, había que viajar a Washington D. C. para consultarlo en la Library of Congress, por ejemplo.

En lo que respecta a personajes de las historias nacionales cuyas vidas no alcanzaron espacio en enciclopedias internacionales, aunque sus nombres no se tradujeran, conocer el motivo de su importancia sí podía ayudar a entender por qué y cómo se les estaba mencionando. Y qué decir de otros desafíos como descubrir a qué lugar actual corresponden numerosos topónimos antiguos. Algunos son relativamente fáciles de identificar, como Siam, muy presente en textos relacionados con la presencia portuguesa en Asia, dado que el topónimo Tailandia data del siglo XX; sin embargo, no ocurre to mismo con topónimos de ciudades o enclaves menos sonados como Mazagão, actual El-Jadida, en Marruecos. Si vamos más atrás en el tiempo, a textos de la Baja Edad Media, como las crónicas de Fernão Lopes, encontraremos nombres cuya evolución podemos conjeturar, pero que debemos confirmar mediante fuentes: Badalhouce>Badajoz, Aljazira>Algeciras, por ejemplo. Por ello, contar con la posibilidad de consultar una fuente como la Grande enciclopédia portuguesa e brasileira era otro privilegio de escasas bibliotecas fuera del mundo lusófono. Aunque esta enciclopedia hoy en día no se pueda consultar de manera digital, sí hay otros recursos fiables disponibles en línea.

De igual modo, gracias a las herramientas que hoy admiten imágenes, quien traduce tiene la posibilidad de ver en fotografías e ilustraciones profesionales aquello que describen los diccionarios, como plantas, árboles, frutos, vegetales, animales, vestuario antiguo, o artefactos fuera de uso. Wikimedia Commons, la mediateca que se conforma con las colaboraciones colectivas en que los derechos de las imágenes se ceden y no hay fines de lucro, ha sido un recurso pionero en este sentido y continúa siendo el archivo más grande de imá- 
genes en la red. En lengua portuguesa, el diccionario Priberam ha comenzado a incorporar fotografías que acompañan las descripciones y que resultan muy útiles tanto para el aprendizaje de la lengua como para la traducción de textos. Esta necesidad de admitir las limitaciones del entendimiento a la hora de leer las descripciones de algo que nunca se ha visto no es nueva, la entendió de manera muy clara el historiador español Gonzalo Fernández de Oviedo, quien acompañó su Historia general y natural de las Indias, islas y Tierrafirme del mar océano (1535) con «algunas ilustraciones de artefactos indígenas, plantas y animales» (Krapovickas, 2010: 92). En los siglos XVI y XVII, un tópico literario fue el establecimiento del parangón entre poesía y pintura. Al respecto:

\footnotetext{
La descripción de los objetos de arte - representaciones verbales de representaciones visuales [...] - es uno de los mecanismos retóricos más efectivos de evocación ${ }^{3}$ visual en la literatura del Siglo de Oro. Gracias a estas transposiciones semióticas dentro del arte verbal el escritor favorece, en términos poéticos y retóricos precisos, una simulación de la opsis (imagen ocular), mediante la propia phantasia del lector (imaginación). (Posada, 2020)
}

Sin embargo, Fernández de Oviedo se dio cuenta de que él no estaba llevando a cabo un ejercicio de evocación porque estaba describiendo realidades desconocidas para los peninsulares, por eso apoyó sus descripciones de las tunas, el plátano, la mandioca, la piña, el manatí o la iguana con dibujos. Celebrar hoy la existencia y la utilidad de los archivos visuales con los que contamos no significa anular nuestra capacidad de abstracción, sino asumir que pintar con palabras es eficaz sólo cuando el referente se conoce. Antes de la revolución tecnológica, pocas situaciones podían resultar tan desafiantes o frustrantes como tener que traducir el nombre de una planta, fruto o animal, particularmente aves y peces, de los que sólo se conocía la taxonomía.

En esta revisión de los elementos más destacados de la transformación del proceso de traducción en la era de la hipertextualidad, he dejado para el final lo que, sin duda, exigía más tiempo e investigación por parte de los traductores que desearan aportar notas explicativas: identificar citas, autores, obras o alusiones de autoridades de la Antigüedad. Lo anterior implicaba cotejar si la fuente estaba citada literalmente, si estaba glosada e incluso si el autor estaba citando de memoria, o por una fuente indirecta. Este trabajo implicaba una inversión de tiempo considerable, que en nuestra época se puede resolver de manera mucho más sencilla, justamente mediante varias ventanas abiertas en el dispositivo de trabajo y una investigación en bibliotecas digitales o libros digitalizados. Son pocas las

${ }^{3}$ Es mi énfasis. 
ocasiones en que definitivamente no es posible detectar la fuente, como cuando los autores son muy imprecisos.

\section{Un proceso hipertextual;}

\section{un resultado analógico}

Hasta ahora, lo expresado celebra el avance de la tecnología computacional y su impacto en el proceso de escritura de un texto, incluida la traducción. Sólo que, mientras que hay una producción literaria pensada para conocerse $e^{4}$ en los soportes tecnológicos existentes, incluidos todos los libros que se pueden descargar en dispositivos como Kindle - traducidos o no -, cuando hablamos de textos antiguos, ese entusiasmo inicial se convierte en preocupación, porque el paso de esos textos a un soporte hipertextual no puede entenderse sólo como una transcripción, y menos todavía como la digitalización de una edición analógica. Es justamente el proceso de traducción de algunas narraciones escritas en el siglo XVI, pero compiladas en el siglo XVII por Bernardo Gomes de Brito en la História trágico-marítima, lo que me ayuda a reconocer que hay un número considerable de textos que podrían beneficiarse de ediciones hipertextuales con rigor filológico, por supuesto. La traducción de ese tipo de textos implica una lectura tan minuciosa que conduce a esta idea porque el proceso es híbrido: bastante analógico aún, mediante la consulta de fuentes que no están digitalizadas, pero con un fuerte componente hipertextual; sin embargo, el resultado es sólo tradicional, analógico. En la mayoría de los casos, la única huella de la riqueza del proceso hipertextual se concentra en notas al pie de página. En otras palabras, el soporte final, en papel, en el que se concreta una investigación en la que no sólo se han leído otros textos impresos, sino bastantes en línea y también se han cotejado imágenes, es insuficiente. Lastima decirlo, por el apego y veneración de siglos que rendimos aún al libro en papel. Sin embargo, aquí habría que recordar la propia historia de la transmisión de los textos a lo largo del tiempo: inscripciones en piedra, papiro, pergamino, papel y ahora pantallas. Tampoco hay que olvidar que el propio libro impreso ha pasado por diversas fases a lo largo de los siglos.

Desde el ámbito de la traducción se pueden notar las limitaciones que he indicado, pero también hay quien lo diga desde el punto de vista de la edición filológica:

\begin{abstract}
Essencialmente, entretanto, não há um objeto que contenha todas as etapas do trabalho que este editor realizou sobre o texto.
\end{abstract}

O trabalho sobre o documento eletrônico tem essa diferença essencial, a meu ver: nessa téc-

\footnotetext{
${ }^{4}$ No me atrevo a usar el verbo leer, puesto que estas creaciones tienden a usar también recursos visuales y sonoros que ensanchan la experiencia intelectual y sensible.
} 
nica, todas as etapas cumpridas pelo editor sobre um texto podem estar reunidas, registradas, em um único objeto - um arquivo eletrônico que contém transcrição, edição, aparato crítico. De fato, um arquivo eletrônico que contém todas as informações sobre um texto, e também, em germe, todas as suas possibilidades de apresentação final.

Essa contingência que pode ser banal para muitos, na minha visão é um divisor de águas entre o trabalho analógico e o trabalho digital com o texto. (Sousa, 2013: 119-120)

Es de esperarse, pues, que la industria editorial se desarrolle en el sentido de la edición hipertextual y que ésta se vuelva más popular y, sobre todo, cumpla a cabalidad con la difusión de un conocimiento fiable, porque, aunque parezca que sólo he considerado positivamente los recursos que encontramos en línea, no todo lo que brilla es oro, pues existen diversas problemáticas con estos recursos electrónicos que comprometen el adecuado acceso a un conocimiento fiable: a) inaccesibilidad, b) dudosa calidad textual, en el caso de las obras literarias, c) información equivocada o incompleta, en el caso de las fuentes que dan información.

a) Inaccesibilidad

Establecemos un vínculo con el libro en papel porque tocarlo nos da la seguridad de un soporte «real». Pero ya se sabe que, si estamos lejos de él, es como si no existiera. En el mundo digital, lo equivalente es el Error 404, el aviso de que no existe más aquello que buscamos. En este sentido, lo menos grave es cuando esto se debe a que los sitios migran, como ocurrió con el de la Imprensa Nacional-Casa da Moeda. Al buscar una edición digital de Menina e moça, uno de los resultados es el de la INCM, pero al dar clic en el enlace sugerido aparece el Error 404 sin que haya un aviso que nos encamine al nuevo sitio (figura 1).

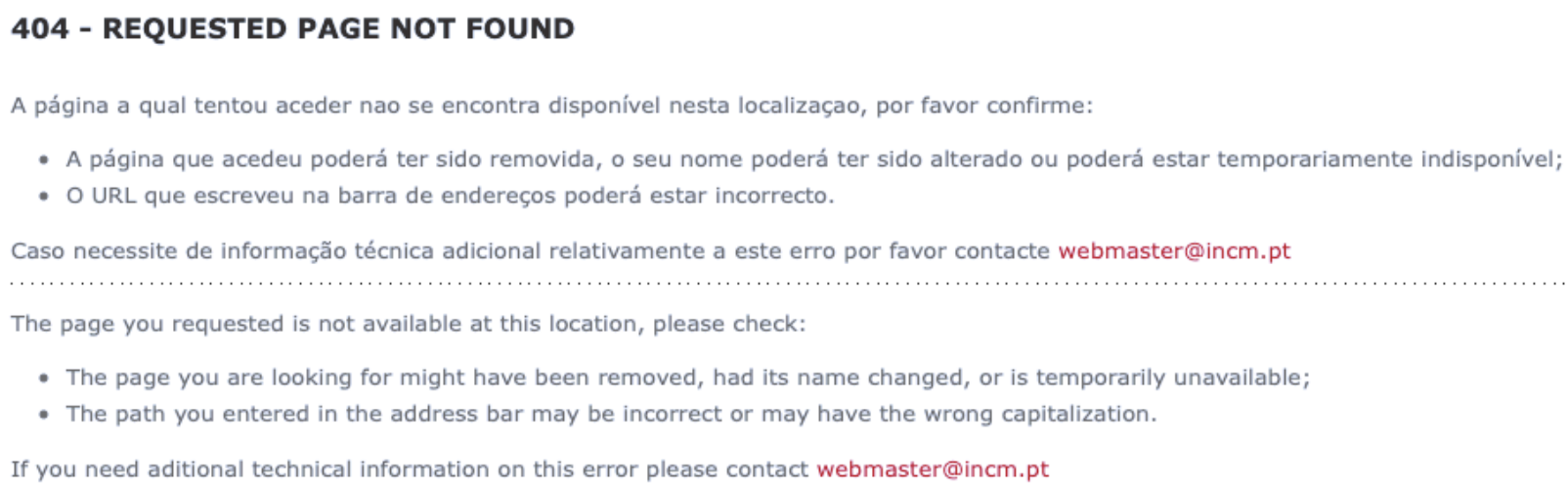

Figura 1 - Error 404 sin indicación de migración del sitio. 
No obstante, la pérdida del enlace, que significa pérdida del acervo, deja a los usuarios ante un silencio que no explica si la desaparición del vínculo se debe a dificultades en el acceso a la tecnología, a falta de presupuesto para mantenerlo activo, o a otros factores.

\section{b) Dudosa o problemática calidad textual}

Pensemos en un hipotético alumno que busca Menina e moça para leer en línea. Los entendidos en la literatura del periodo tienen idea de la difícil trayectoria del texto, pero un estudiante joven, no. ¿Qué va a encontrar? Quien acuda al link que provee la Universidade de Macau, que reproduce la $2 .^{a}$ edición de la que preparó Delfim Guimarães (1916), verá que el título de la obra es Saudades. História de menina e moça. Cuando empiece a leer la obra se encontrará con este texto: «Menina e moça, me levaram de casa de meu pae para longes terras». Quien, por su parte, prefiera la edición que ofrece el sistema de bibliotecas de la Universidade da Amazônia encontrará que el título es simplemente Menina e moça y el inicio es éste: «Menina e moça me levaram de casa de minha mãe para muito longe». Este último ejemplo no consigna cuál es la fuente de la que se vale para el texto que está disponible, lo que hay es simplemente el título y el texto. El PDF gratuito que ofrece la INCM no se encuentra entre los primeros resultados que se despliegan al hacer la búsqueda. Esta edición, que se intitula História de Menina e Moça, avisa que adopta la edición de Ferrara de 1554 como texto base, cuenta con una introducción, nota bibliográfica, edición del texto y glosario por parte de Marta Marecos Duarte y se acompaña también de una breve nota de Carlos Reis, coordinador de la colección. Aunque bastante fiable, no es una edición crítica (Duarte, 2015: 39) y, como toda la colección Biblioteca Fundamental da Literatura Portuguesa, actualiza la ortografía según el Acordo Ortográfico de 1990. Por eso, su comienzo es: «Menina e moça me levaram de casa de minha mãe para muito longe» (Ribeiro, 2015: 55). En una línea parecida está la edición crítica de Carrasco González (2008), sólo conseguible en papel. Lleva como título: Menina e moça ou Saudades y el comienzo es: «Minina e moça me levaram de casa de minha mai para muito longe» (Ribeiro, 2008: 91). En este último caso, hay un robusto aparato crítico que explica las variantes del texto a partir de los testimonios (manuscritos e impresos) del siglo XVI. Como se ha observado, es evidente que las fuentes que se encuentran en línea producen confusión a quien suela leer atentamente debido a su carácter desigual: unas carecen de rigor, no son fiables porque ni siquiera cuentan con notas; pero la mejor no es edición crítica. Los despistados que se dejen llevar por el primer resultado van directo al error, porque esas fuentes son un obstáculo para el conocimiento. Un texto como el de Bernardim Ribeiro se vería profundamente beneficiado de una edición crítica hipertextual que zanjara en definitiva las confusiones. 
c) Información equivocada o incompleta

Al inicio de esta revisión aludí con elogios a la idea base de Wikipedia. Su interfaz es lo más cercano al ideal de una edición crítica hipertextual, al contar con numerosos recursos patentes a la vista; no obstante, el hecho de ser un proyecto en donde los creadores de los contenidos no son especialistas en aquello que editan, implica que algunas aportaciones sean perfectibles. ${ }^{5}$ Ilustro con un ejemplo que me resulta bastante familiar. Si se busca en la red información general sobre la Historia trágico-marítima, aparecerán los resultados en Wikipedia. La entrada cuenta con versiones sólo en tres lenguas: inglés, latín y portugués. En los tres casos, las fuentes que sirven de apoyo son distintas, y aunque con el tiempo ha ido mejorando bastante la entrada en la versión en portugués, hay algunas imprecisiones que se explican por la ausencia de determinados estudios en el aparato de fuentes de apoyo, sobre todo los de Boxer, Giulia Lanciani o António Manuel de Andrade Moniz, obras esenciales para dar la información completa y correcta.

\section{Hacia ediciones críticas}

y traducciones hipertextuales

Hoy en día, profesores, grupos de investigación y traductores tenemos que familiarizarnos con diversos tipos de herramientas tecnológicas para llevar a cabo nuestro trabajo. Por su parte, las generaciones que procuramos formar superan nuestras habilidades en ese sentido de manera frecuente y están totalmente familiarizadas con los recursos tecnológicos. No obstante, y a partir de mi experiencia docente en México - que no será muy diferente de la del resto del mundo -, sé que algunos de esos estudiantes no están completamente sensibilizados a no caer en la trampa de la inmediatez y no suelen comparar las fuentes. Estos jóvenes usuarios deberían de comprender que el hecho de que numerosas obras de consulta se hayan mudado de soporte, no implica que se haya transformado el espíritu de la investigación, que persigue un conocimiento basado en la veracidad y fiabilidad de las fuentes. Por eso, la transmisión fiable de un patrimonio verbal es el punto de partida para todo ejercicio de crítica e interpretación que se juzgue serio. En lo que a ediciones críticas se trata, éstas casi son inconseguibles en

\footnotetext{
${ }^{5}$ Es verdad que ha mejorado mucho el proceso de creación de contenidos en Wikipedia, una fuente que, querámoslo o no, los alumnos terminan consultando. En un principio, prácticamente cualquier persona podía crear entradas o colaborar con contenidos. Esto ha ido cambiando y se han formado grupos de editores que participan en editatones en los que se eligen temas para crear entradas o se editan las existentes para mejorarlas. El asunto es que estas personas son editores, pero no especialistas en los temas que crean o editan. Actúan de buena voluntad, pero no necesariamente están actualizados en relación con las fuentes, que son obligatorias para respaldar los contenidos añadidos. Los especialistas en los temas tendrían que convertirse en editores de recursos wiki para poder ser ellos quienes realizaran las colaboraciones. Otro asunto que también resulta problemático es que muchas veces los vínculos que remiten a esas fuentes que respaldan las entradas están rotos, por lo que no es posible corroborar la información.
} 
papel, si es que se llevaron a cabo hace años, así que menos aún se encuentran en línea,por lo cual la mayoría de las ediciones asequibles son trabajos superados, 0 «nunca tuvieron un valor científico» (Lucía Megías, 2009: 8). Aunque se han señalado durante años los trabajos que la tecnología permitiría llevar a cabo, no está de más insistir en ello, porque también es un deber intelectual, profesional, educativo e institucional producir un conocimiento que se adapte a los tiempos. Digitalizar un libro no significa que esa digitalización sea una edición hipertextual, pues

un hipertexto formado sólo de texto (lo cual no deja de ser extraño) lo que realmente demostraría es que no está utilizando todas las posibilidades inherentes al medio, sino simplemente trasladando determinada estructura impresa a otro soporte de visualización, el ordenador, que en su esencia contiene la posibilidad de la combinación de medios diversos para crear un mensaje. (Pérez Marco, 2003: 121)

Las ediciones hipertextuales aún son una realidad exclusiva de grandes presupuestos y reservadas a obras o autores clásicos, es verdad, pero también es correcto dedicar esos esfuerzos a preservar en los nuevos soportes un legado cultural que se ha transmitido por otras vías a través de los siglos. Lo ideal sería proporcionar materiales digitales fiables, especialmente ediciones críticas hipertextuales a la manera de algunas ya existentes, que pueden ilustrar que el camino para la realización de este tipo de proyectos implica la coordinación de disciplinas distintas como la filología, el diseño web y la tecnología computacional. En este momento, al menos, pensar que el filólogo puede hacerlo solo es equivocado e ingenuo.

Un ejemplo modélico es el Oregon Petrarch Open Book (OPOB), que se puede consultar bajo registro. Este proyecto tiene como base gnoseológica la noción de punto de partida de Auerbach, e incluso adapta a la filología la concepción de autopoiesis, de los biólogos chilenos Humberto Maturana y Francisco Varela, para presentar la edición hipertextual de Rerum vulgarium fragmenta, de Petrarca (Lollini, 2011). El punto de partida es el poema individual, rodeado de una serie de posibilidades como traducciones, reescrituras, herramientas para la mejor comprensión del texto (paráfrasis, comentarios, anotaciones, etc.), información concreta de cada composición (metro, fecha, lugar, palabras clave), así como archivos sonoros y visuales, y ensayos académicos que aludan a la composición. La edición crítica ya existía y se puede consultar a la par de la edición facsimilar y diplomática.

En la tradición literaria portuguesa, la base de datos de las Cantigas Medievais Galego Portuguesas, que ha coordinado Graça Vieira Lopes, es lo más cercano al proyecto anterior. En la misma línea va el Universo de Almourol, de Aurelio Vargas Díaz Toledo, pero en rela- 
ción con los libros de caballerías portugueses. Sin duda se trata de recursos de muchísima utilidad, pero qué bueno sería que existiera un proyecto semejante a éstos para leer, estudiar y comprender mejor Os Lusíadas, por ejemplo. Imaginemos comprender cada estrofa de los diez cantos, mediante la prosificación, el comentario, la explicación de las alusiones culturales, de las figuras retóricas, así como de la métrica, todo esto enriquecido con los textos críticos al respecto. Pero una edición crítica hipertextual también sería útil para la comprensión de obras más cercanas a nosotros en el tiempo, debido a que su naturaleza demanda un tipo de edición más abarcador que el papel, como Metamorfoses, de Jorge de Sena y varias de Murilo Mendes (al menos Retratos-relámpago, A invenção do finito, o Janelas verdes). A esto añádase la manera en que se beneficiarían numerosos textos si hubiera traducciones hipertextuales, con vínculos que remitieran a imágenes, mapas o diccionarios.

En este momento, los estudios literarios tienen aún en los acervos impresos los pilares de la investigación, y es verdad que en no pocos casos aún falta por hacer la edición crítica analógica; sin embargo, la transmisión del conocimiento en términos masivos es híbrida: analógica y digital, y no hay vuelta atrás. Esa hibridez ya se vivió en los siglos XVI y XVII, cuando convivieron la imprenta, el manuscrito y la transmisión oral. Esa hibridez igualmente forma parte del proceso de edición y traducción contemporáneos. Por eso, lo ideal sería que de manera muy puntual el formato final fuera uno que recuperara los materiales que ayudan a la comprensión del texto, no que prescindiera de ellos.

Hoy en día casi nadie lee periódicos impresos, nos parece natural hacerlo en línea; no obstante, nuestra actitud no es la misma al tratarse de libros digitales. Por lo tanto, dos son los elementos esenciales para aprovechar las posibilidades de la tecnología: un cambio en nuestra actitud, esto es, derribar prejuicios, y una mayor fiabilidad en los materiales que estén disponibles al alcance de un clic. Lograr esa fiabilidad es una cuestión de presupuesto y ciencia, pero es un esfuerzo que vale la pena para proteger y aprovechar la ubicuidad de la tecnología y de ese modo difundir el legado cultural de los pueblos. Las visitas a los archivos y bibliotecas portugueses o brasileños seguirán siendo indispensables para quien llegue a un alto grado de especialización, pero ediciones hipertextuales fiables a las que se pueda acceder desde cualquier lugar del mundo es el mayor homenaje que una cultura puede rendir a su acervo cultural, por ahora.

\section{Bibliografía}

\section{Impresa}

Ribeiro. B. (2008). Menina e moça ou Saudades. (Ed. de J.M. Carrasco González). Angelus Novus. Coimbra;

Simon, S. (2019). The Translator's Study. Picturing Translation from Saint Jerome to Nurith Aviv. Translation site. A Field Guide. Routledge, London/New York. 


\section{Digital}

Dasilva, X.M. da (2017). La traducción literaria entre español y portugués en los siglos XVI y XVII". E-Spania. Revue Interdisciplinaire d'Études Hispaniques Médiévales et Modernes, 27. Accedido el 20 de mayo de 2021, en: https://journals.openedition.org/e-spania/26695;

Duarte, M.M. (2015). Introdução. Em: B. Ribeiro. História de menina e moça. (Introd., ed., glossário, bibliografia e notas de Marta Marecos Duarte). INCM. Lisboa. Accedido el 29 de junio de 2021, en: https://imprensanacional.pt/ wp-content/uploads/2021/04/BernardimRibeiro_MeninaEMoca.pdf;

Falcón, A. (2016). Traducir, aclimatar, argentinizar: la importación literaria en 1969. Cuadernos LIRICO, 15. Accedido el 2 de mayo de 2021, en: https://journals.openedition.org/ lirico/2947;

Krapovickas, A. (2010). Las ilustraciones de la Historia General y Natural de las Indias, Islas y Tierrafirme del mar océano de Gonzalo Fernández de Oviedo y Valdés. Bonplandia. 19 (1): 91-96. Accedido el 20 de mayo de 2021, en: https://revistas.unne.edu.ar/index.php/bon/ article/view/1337/1109;

Lollini, M. (2011). Return to Philology and Hypertext in and around Petrach's Rvf. Humanist Studies \& the Digital Age, 1 (1). Accedido el 11 de junio de 2021, en: https:// scholarsbank.uoregon.edu/xmlui/bitstream/ handle/1794/11417/Return\%20to\%20Philology.pdf?sequence=1 \&isAllowed=y;

Lopes, G.V. et al. (2011-). Cantigas Medievais Galego-Portuguesas [base de dados on line]. Instituto de Estudos Medievais FCSH/NOVA. Accedido el 2 de mayo de 2021, en: https:// cantigas.fcsh.unl.pt;

Losada Soler, E. (2001). La (mala) fortuna de Eça de Queiroz en España: las traducciones de Valle Inclán. En: Luis Pegenaute (ed.). La traducción en la Edad de Plata. PPU, Barcelona. Accedido el 10 de junio de 2021, en: http:// hte.upf.edu/wp-content/uploads/La-traduccion-en-la-Edad-de-Plata.pdf;
Lucia Megías, J. M. (2009). La edición crítica hipertextual. Hacia la superación del incunable del hipertexto.Lecturas y textos en el siglo XXI:los nuevos caminos de la críticatextual. En prensa.Accedido el 2 de mayo de 2021,en: https://core.ac.uk/ download/pdf/19712025.pdf / https://eprints.u cm.es/id/eprint/8687;

Nelson, T. (1965). A File Structure for the Complex, the Changing and the Indeterminate. ACM 20th National Conference Proceedings. Accedido el 1 de junio de 2021, en: https://monoskop. org/File:Nelson_Ted_1965_A_File_Structure_ for_the_Complex_the_Changing_and_the_Indeterminate.pdf;

Oregon Petrarch Open Book (OPOB) (2003-). University of Oregon. Accedido el 4 de junio de 2021, en: https://petrarch.uoregon.edu;

Pérez Marco, S. (2003). El concepto de hipertexto en el periodismo digital: análisis de la aplicación del hipertexto en la estructuración de las noticias de las ediciones digitales de tres periódicos españoles (www.elpais.com, www.elmundo.es, wwwabc.es). Tesis de Doctorado en Periodismo. Universidad Complutense de Madrid. Madrid. 572 pp. Accedido el 2 de mayo de 2021, en: https://eprints.ucm.es/id/eprint/4668;

Ponce de León Romeo, R. (2009). Los inicios de la enseñanza-aprendizaje del portugués en España: Breves consideraciones sobre el Primero y segundo curso de portugués (Madrid 1876) de Francisco de Paula Hidalgo. Documents pour l'histoire du Français Langue Étrangère ou Seconde, 42. Accedido el 2 de mayo de 2021, en: https://journals.openedition.org/ dhfles/757;

Posada, A. (2020). ¿Écfrasis o hipotiposis?: Enargeia y retórica visual en la poesía del Siglo de Oro. e-Spania. Revue Interdisciplinaire d'Études Hispaniques Médiévales et Modernes, 37. Accedido el 2 de diciembre de 2021, en: https://journals.openedition.org/e-spania/36222?lang=pt;

Ribeiro, B. (2015). História de menina e moça. (Introd., ed., glossário, bibliografia e notas de Marta Marecos Duarte). INCM. Lisboa. Accedido 
el 29 de junio de 2021, en: https://imprensanacional.pt/wp-content/uploads/2021/04/ BernardimRibeiro_MeninaEMoca.pdf;

Ribeiro, B. (s. d.). Menina e moça. Universidade da Amazônia. Accedido el 20 de mayo de 2021, en: http://www.portugues.seed.pr.gov.br/arqui vos/File/leit_online/bernardin_rib.pdf.

Ribeiro, B. (1916). Saudades: História de menina e moça. Guimarães \& Ca. Lisboa. Recuperado el 20 de mayo de 2021, en: https://library. um.edu.mo/ebooks/b33463785.pdf;
Sousa, M.C. (2013). A filologia digital em língua portuguesa. Alguns caminhos. Em: Gonçalves M.F. e Banza,A.P. (eds.). Património textual e humanidades digitais. Da antiga à nova filologia. Publicações do Cidehus. Évora. Accedido el 11 de junio de 2021, en: https://books.openedition.org/cidehus/1089.

Vargas Díaz Toledo, A. (2017-). Universo de Almourol. Base de dados da matéria cavaleiresca portuguesa dos séculos XVI-XVIII. Recuperado el 25 de octubre de 2021, en: http://parnaseo. uv.es/UniversoDeAlmourol/. 